\title{
CLIMATE CHANGE ADAPTATION IN AFRICA: A MICROECONOMIC ANALYSIS OF LIVESTOCK CHOICE ${ }^{1}$
}

Sungno Niggol Seo and Robert Mendelsohn ${ }^{2}$

World Bank Policy Research Working Paper 4277, July 2007

The Policy Research Working Paper Series disseminates the findings of work in progress to encourage the exchange of ideas about development issues. An objective of the series is to get the findings out quickly, even if the presentations are less than fully polished. The papers carry the names of the authors and should be cited accordingly. The findings, interpretations, and conclusions expressed in this paper are entirely those of the authors. They do not necessarily represent the view of the World Bank, its Executive Directors, or the countries they represent. Policy Research Working Papers are available online at http://econ.worldbank.org.

\footnotetext{
${ }^{1}$ An earlier version of this Working Paper was published as CEEPA Discussion Paper number 19.

${ }^{2}$ University of Aberdeen Business School, United Kingdom and School of Forestry and Environmental Studies, Yale University, 230 Prospect Street, New Haven, CT 06511, USA, Seo email: niggol.seo@abdn.ac.uk; Mendelsohn phone: 203-432-5128, e-mail: Robert.mendelsohn@yale.edu.

This paper was funded by the GEF and the World Bank. It is part of a larger study on the effect of climate change on agriculture in Africa, managed by the World Bank and coordinated by the Centre for Environmental Economics and Policy in Africa (CEEPA), University of Pretoria, South Africa.
} 


\section{SUMMARY}

This paper uses quantitative methods to examine the way African farmers have adapted livestock management to the range of climates found across the African continent. We use logit analysis to estimate whether farmers adopt livestock. We then use three econometric models to examine which species farmers choose: a primary choice multinomial logit, an optimal portfolio multinomial logit, and a demand system multivariate probit. The 'primary animal' model examines the choice of the single species that earns the greatest net revenue on the farm. The 'optimal portfolio' model examines all possible combinations of animals that farmers can choose. The demand system model examines the probability that a farmer will choose a particular species.

Using data from over 9000 African livestock farmers in ten countries, the analysis finds that farmers are more likely to choose to have livestock as temperatures increase and as precipitation decreases. Under cooler temperatures and wetter conditions, in contrast, they favor crops. Across all methods of estimating choice, livestock farmers in warmer locations are less likely to choose beef cattle and chickens and more likely to choose goats and sheep. As precipitation increases/decreases, cattle and sheep decrease/increase but goats and chickens increase/ decrease. Places with more rain in Africa are more likely to be forest than savanna. The savanna favors cattle and sheep whereas the forest favors goats and chickens.

We then simulate the way farmers' choices might change with a set of uniform climate changes and a set of climate model (AOGCM) scenarios. The uniform scenarios predict that warming and drying would increase livestock ownership but that increases in precipitation would decrease it. Warming would encourage livestock farmers to shift from beef cattle and chicken to goats and sheep. Increases/decreases in precipitation would cause livestock owners to decrease/increase dairy cattle and sheep but increase/decrease goats and chickens. The AOGCM (Atmospheric Oceanic General Circulation Model) climate scenarios predict a decrease in the probability of beef cattle and an increase in the probability of sheep and goats, and they predict that more heattolerant animals will dominate the future African landscape.

Comparing the results of the three methods of estimating species selection reveals that the 'primary animal', 'optimal portfolio', and 'demand system' approaches yield similar results. The demand system and optimal portfolio analyses appear slightly more responsive because they measure the presence of a particular species, rather than whether it is the primary animal. The optimal portfolio approach also differs from the other two methods in predicting warming will have a harmful effect on dairy cattle and goats and a larger beneficial effect on sheep. 


\section{TABLE OF CONTENTS}

Section $\quad$ Page

1 Introduction $\quad 4$

2 Theory 4

3 Data and empirical specification $\quad 7$

4 Empirical results 8

5 Climate change simulations 10

6 Conclusion and policy implications $\quad 12$

$\begin{array}{ll}\text { References } & 14\end{array}$ 


\section{Introduction}

As it has become clear that warming has already begun and will continue into the future (Houghton et al. 2001), the climate literature has gradually begun to address the critical question of adaptation (McCarthy et al. 2001). There are papers that discuss whether adaptation will anticipate climate change or simply react to it (Ausubel 1991; Yohe et al. 1996; Klein et al. 1999; Smit \& Pilifosova 2001). There are papers that discuss whether adaptation will be autonomous or require public action (Smit et al. 1996; Klein et al. 1999; Leary 1999; Burton 2000; Pittock \& Jones 2000; Bryant et al. 2000; Smit et al. 2000; Barnett 2001). There are papers that argue that adaptation will reduce the damages and increase the benefits of warming (Mendelsohn et al. 1994; Reilly et al. 1996; Adams et al. 1999). There are papers that argue whether or not adaptation will be efficient (Mendelsohn 2000; Kelly et al. 2005). However, most of this literature is qualitative and theoretical. What is consistently missing in this literature is empirical evidence. How will people adapt? What will they do in what circumstances?

This study examines the behavior of farmers in Africa and explores how they have adapted livestock management to the various climates across Africa. The paper specifically examines whether farmers will adopt livestock and which species they will choose. We are specifically interested in whether these decisions depend on climate.

In the Section 2 we compare three alternative models of species choice: 'primary animal' multinomial logit, 'optimal portfolio' multinomial logit, and 'demand system' multivariate probit. The primary animal analysis examines the choice of the single species that earns the greatest net revenue on the farm. The optimal portfolio approach examines all possible combinations of animals that farmers can choose. The demand system model examines the probability that a farmer will choose a particular animal.

In Section 3 we briefly discuss the data that has been collected across ten countries in Africa and in Section 4 we use the data to estimate econometric models of each livestock model. In Section 5 we use these estimated equations to simulate the way farmer decisions would change if climate changed. We explore some simple uniform climate scenarios and some complex climate model scenarios from Atmospheric Oceanic General Circulation Models (AOGCMs). The paper concludes with some general observations and policy implications.

\section{Theory}

We assume that a livestock farmer chooses the outputs and inputs that maximize net revenue subject to the prices, climate, soils and other external factors that he or she faces. The farmer must determine whether or not it is profitable to engage in livestock management and also choose which species to manage.

The first choice is a discrete choice of whether or not to engage in livestock management. Suppose the profit from managing livestock is given by Error! Objects cannot be created from editing field codes. where $\mathrm{X}$ is a vector of regressors composed of climates, soils and other socio-economic factors. Suppose the disturbance Error! Objects cannot be created from 
editing field codes. is known to the households and unknown to the econometrician, but the cumulative distribution function $(\mathrm{CDF})$ is a function Error! Objects cannot be created from editing field codes.that is known up to a finite parameter vector. The profit maximizing farms will then choose to have livestock if Error! Objects cannot be created from editing field codes. or Error! Objects cannot be created from editing field codes. The probability that this occurs, given X, is Error! Objects cannot be created from editing field codes.. If Error! Objects cannot be created from editing field codes.is a standard logistic CDF, then after the integration the probability can be expressed as

\section{Error! Objects cannot be created from editing field codes.}

The likelihood of observing our sample can be constructed and the maximum likelihood estimators are obtained by a nonlinear optimization technique (Chow 1984, McFadden 1999).

The farmer then compares the profits from different species in order to choose which one to adopt. We compare three models of this choice. The primary animal model assumes that the only choice of importance to the farmer is the primary animal, i.e. the species that earns the greatest net revenue on the farm. The farmer must consequently choose a single primary animal from the list of available species. The portfolio model examines all possible combinations of species that a farmer can choose. This model treats specific combinations of species as distinct choices. The list of choices for both of these models is mutually exclusive. The farmer can select only one choice.

We assume that farmer $i$ 's profit in choosing the $j_{t h}$ animal $(\mathrm{j}=1,2, \ldots, \mathrm{J})$ is

\section{Error! Objects cannot be created from editing field codes.}

(2)

where $K$ is a vector of exogenous characteristics of the farm and $S$ is a vector of characteristics of farmer $i$. For the portfolio model, the $j_{t h}$ choice could be a combination of animals. The vector $K$ could include climate, soils, and access variables and $\mathrm{S}$ could include the age of the farmer and family size. The profit function is composed of two components: the observable component $V$ and an error term, $\varepsilon$. The error term is unknown to the researcher, but may be known to the farmer. The farmer will choose the livestock that gives him the highest profit. Defining Error! Objects cannot be created from editing field codes., the farmer will choose $j_{t h}$ animal over all other animals if: 
$\pi^{*}\left(Z_{j i}\right)>\pi^{*}\left(Z_{k i}\right)$ for all $\mathrm{k} \neq \mathrm{j}$. [or if $\varepsilon\left(Z_{k i}\right)-\varepsilon\left(Z_{j i}\right)<V\left(Z_{j i}\right)-V\left(Z_{k i}\right)$ for $\mathrm{k} \neq \mathrm{j}$ ]

More succinctly, farmer $i$ 's problem is:

\section{Error! Objects cannot be created from editing field codes.}

The probability Error! Objects cannot be created from editing field codes. for the $j_{t h}$ animal to be chosen is then

$$
\begin{aligned}
P_{j i} & =\operatorname{Pr}\left[\varepsilon\left(Z_{k i}\right)-\varepsilon\left(Z_{j i}\right)<V_{j}-V_{k}\right] \\
& =\operatorname{Pr}\left[\varepsilon\left(Z_{k i}\right)<\varepsilon\left(Z_{j i}\right)+V_{j}-V_{k}\right] \forall \mathrm{k} \neq \mathrm{j} \text { where } \mathrm{V}_{\mathrm{j}}=\mathrm{V}\left(\mathrm{Z}_{\mathrm{ji}}\right)
\end{aligned}
$$

If $V$ is linear in parameters, this integration reduces to a simple form:

\section{Error! Objects cannot be created from editing field codes.}

(6)

which gives the probability that farmer $i$ will choose alternative $\mathrm{j}$ among $\mathrm{J}$ alternatives (McFadden 1973, Chow 1984, McFadden 1999, Train 2003). The parameters can be estimated by the Maximum Likelihood method, using an iterative nonlinear optimization technique such as the Newton-Raphson method. These estimates are CAN (Consistent and Asymptotically Normal) under standard regularity conditions (McFadden 1999).

The third approach estimates a system of demand equations for each animal. The farmer determines whether a species is profitable. The more profitable the species, the more likely it is that the farmer will adopt it. We estimate this system of equations using multivariate probit. Note that the choices in this framework are not mutually exclusive and farmers can select more than one species. Let $Y_{i j}$ denote the binary response of $i_{t h}$ farmer on the $\mathrm{j}_{\text {th }}$ animal and let $Y_{i}=\left(Y_{i l}, \ldots, Y_{i J}\right)$ denote the collection of responses on all $J$ animals. According to the multivariate probit model (Chib \& Greenberg 1998), the probability that $Y_{i}=y_{i}$, conditioned on parameters $\beta, \Sigma$, and a set of covariates $x_{i j}$, is given by 


$$
P\left(Y_{i}=y_{i} \mid \beta, \Sigma\right)=\int_{A_{i J}} \ldots \int_{A_{i 1}} \phi_{J}\left(t_{1}, \ldots, t_{J} \mid 0, \Sigma\right) d t_{1} \ldots d t_{J}
$$

Where $\phi_{J}(t \mid 0, \Sigma)$ is $J$-variate normal distribution with mean vector 0 and correlation matrix $\Sigma=\left\{\sigma_{j k}\right\}$, and $\mathrm{A}_{\mathrm{ij}}$ is the interval

$$
A_{i j}= \begin{cases}\left(-\infty, x_{i j}^{\prime} \beta_{j}\right) & \text { if } y_{i j}=1, \\ \left(x_{i j}^{\prime} \beta_{j}, \infty\right) & \text { if } y_{i j}=0 .\end{cases}
$$

All three approaches to selecting species are theoretically sound. However, each approach is best suited to particular circumstances. The primary animal approach is well suited when the secondary animals are of little economic importance. The portfolio approach is well suited when there are few choices but specific combinations of species are unique and important. The demand system approach is best suited to the case when the choice of each species is independent of the choice of others. The researcher often cannot determine in advance which method is to be preferred. We consequently compared all three methods using the same data.

The primary animal analysis is clearly warranted when there is a great deal of specialization, i.e. when secondary animals are of little economic importance. The portfolio approach is especially useful when specific combinations of animals are unique and important; for example, it may be easy to manage two species together. One problem with the portfolio approach, however, is the possibility of too many choices. The number of combinations $\left(2^{n}-1\right)$ increases rapidly with the number of choices, $\mathrm{n}$. In our dataset, the five primary animals to choose from led to 31 possible combinations. Estimating coefficients across this many choices is demanding. Finally, the demand system approach is well suited for determining the presence of an animal on a farm. However, this approach implicitly assumes the choice of each species is independent of the other choices.

\section{Data}

The dataset for this analysis comes from an extensive economic survey involving over 9000 farmers in ten African countries: Burkina Faso, Cameroon, Egypt, Ethiopia, Ghana, Kenya, Niger, Senegal, South Africa and Zambia. Data was gathered from Zimbabwe but the livestock observations had to be dropped because of the turbulent conditions in this country during the survey period. The data was collected for the GEF project studying the impact of climate change 
on African agriculture (Dinar et al. 2006). A more detailed description of the design of the survey, data collection, data cleaning and the set of variables measured is available (Kurukulasuriya \& Mendelsohn 2006; Seo \& Mendelsohn 2006). This section briefly summarizes the key highlights and variables used in this study.

Our dataset records information on livestock production and transactions, livestock product production and transactions, and relevant costs. The data indicate that the five major types of livestock in Africa are beef cattle, dairy cattle, goats, sheep and chickens. Other less frequent animals recorded include breeding bulls, pigs, oxen, camels, ducks, guinea fowl, horses, bees and doves. The major livestock products sold were milk, beef, eggs, wool and leather. Others included butter, cheese, honey and manure. Annual revenue is the sum of livestock sold and livestock products sold. Net revenue was calculated by subtracting costs from gross revenue. The five major animals account for $86 \%$ of all livestock revenue. We consequently limited the analysis to these five animals.

Climate data came from two sources: US Defense Department satellites and weather station observations. We relied on the satellite data for temperature observations and the ground station data for interpolated precipitation observations (Mendelsohn et al. 2006). Soil data were obtained from the FAO digital soil map of the world CD ROM. The data was extrapolated to the district level using GIS (Geographical Information System). The dataset reports 116 dominant soil types.

\section{Empirical results}

The first decision is the binary choice of whether or not to engage in livestock management. This decision was estimated across the full dataset of 9000 farms from the survey. Table 1 shows the results of the logit analysis of livestock management. Three tests of the global significance of the model are all highly significant. The coefficients reveal that several factors affect whether or not a farm adopts livestock. West African farms are less likely to choose to engage in livestock management. The probability of owning livestock increases with available pasture in the district. Farmers in countries with higher Islam populations and higher population densities are also more likely to own livestock.

The most important result in Table 1, however, concerns the climate coefficients. Climate influences livestock ownership. All the climate coefficients except the linear term on winter temperature are significant. The shapes of the response functions to temperature are complex. The livestock response to summer temperature is hill-shaped but the response to winter temperature is U-shaped. In contrast, the livestock response to both summer and winter precipitation is U-shaped.

In Figures 1a and 1b, we plot the estimated probabilities of choosing livestock over a range of annual temperatures and precipitation levels. The model predicts that the probability of owning livestock increases as annual temperature increases but decreases as annual rainfall increases. Farmers choose livestock more often when it is hotter and dryer. This result is not unique to Africa and can be observed across many landscapes, including the American West, southern Latin America and western Asia. Livestock have a competitive advantage over crops in hot and 
dry landscapes (Viglizzo et al. 1997, Swinton 1988, Fafchamps et al. 1998, Evenson 2005). Although pasture may be more productive if located in cooler and wetter climates, the land becomes more profitable for crops. Further, grasslands turn to forests. Finally, hot moist conditions also bring on animal diseases. Hence, we observe in this data that farmers adapt to hot and dry climates by shifting to livestock. Note, however, that there is a limit to how dry landscapes can become and still remain suitable for livestock.

The second analysis examines the choice of primary animal. In the data, farmers can pick any combination from the five animals, and more than one can be chosen. However, our data indicate that farmers tend to specialize. The primary animal generated $88 \%$ of total livestock income in the sample. Our first model examines the choice of a primary animal across different climates using multinomial logit. Table 2 shows the regression results for the five primary animals. The base case is a household with chickens. Most of the coefficients are very significant and the test of global significance of the model verifies that the model is highly significant. West African farmers are less likely to own beef cattle and especially dairy cattle. This may be because of problems the West African farmers have with animal diseases. Instead of cattle, West Africans are more likely to own goats and especially sheep. Large farmers in Africa specialize in dairy and especially beef cattle. These farmers may be more vulnerable to climate change to the extent that these species are particularly climate sensitive. Electricity is associated with beef cattle, dairy cattle, and sheep and may be a proxy for market access or a commercial farm. The climate variables are mostly significant. The probability response to summer temperature is hill-shaped in the case of beef cattle and U-shaped otherwise. The response to winter temperature is Ushaped for beef cattle and sheep and hill-shaped for dairy cattle and goats.

Because the climate response functions are quadratic, it is helpful to see these in graphic form. Figure 2a graphs the relationship between the probability of choosing a species and annual temperature for the primary animal regression. Note that the mean temperature in Sub-Saharan Africa is $22^{\circ} \mathrm{C}$. The probability of choosing beef cattle decreases rapidly as temperature rises, as does the probability of choosing dairy cattle. In contrast, the probability of choosing goats and sheep climbs as temperature rises. With chickens, the estimated probability is hill-shaped, with a maximum at the current mean temperature of Africa. The graph clearly reveals that the choice of animals in Africa today is very temperature sensitive.

Figure $2 \mathrm{~b}$ displays the estimated relationship between the probability of choosing an animal and annual precipitation for the primary animal approach. Beef cattle, dairy cattle and sheep all decrease as precipitation increases. More rain increases the probability of disease and, perhaps more importantly, shifts the ecosystem from savanna to forest (Sankaran et al. 2005). All three of these animals are clearly more productive in grasslands. In contrast to the above results, goats and especially chickens are more likely to be chosen as rain increases. Goats may be able to forage more successfully than other large animals in wetter climates.

The second species choice model, the 'optimal portfolio' approach, examines all combinations of animals from the five animals. All of these choices are then estimated using multinomial logit regression. We examine all chosen combinations with sufficient observations to estimate a regression. Altogether there are 14 combinations in Table 3 . The base case is the households that have chosen dairy cattle, goats, sheep and chickens together. Climate parameter estimates are not directly comparable to those using the other methods. Looking at just the households who 
selected only one animal, the probability response to summer temperature is hill-shaped except for dairy cattle. This is in contrast with the other analyses in which summer temperature has a Ushaped response function except for beef cattle. The response to precipitation is similar across models. Precipitation has a U-shaped response in most cases. Large farms are more likely to choose any of the combinations, whereas farms with electricity are less likely to choose any combination of animals, with a few exceptions.

The plots for the 'portfolio' results for temperature in Figure 3a and precipitation in Figure $3 \mathrm{~b}$ reveal similar shapes to Figures $2 \mathrm{a}$ and $2 \mathrm{~b}$. We construct these plots by estimating the probability for each combination of animals given a particular temperature or precipitation level. We then sum the probabilities of all the combinations that entail one particular species, and repeat this calculation for each species. Note that this approach detects the probability that a species is present at the farm. Higher temperatures reduce the probability of choosing both beef and dairy cattle and increase the probability of choosing goats and sheep. These temperature results are quite similar to the findings of the primary animal approach, except that dairy cattle have a much stronger negative temperature effect.

The portfolio approach, however, does not give the same precipitation responses as the primary animal approach. With the portfolio approach, the probabilities of choosing beef and dairy cattle are not sensitive to precipitation and the probabilities of choosing goats and sheep decrease with precipitation. The choice of whether or not to own a species is quite different from the choice of which species should be the primary animal. It is possible that the primary animal choice is motivated more by commercial interests whereas the choice of secondary animals may be for household use. For example, even when cattle are not a particularly good commercial investment, households may still want a few of them for personal use.

The third approach we use to model species selection is the demand system approach. We estimate a system of probit equations for each species and account for possible correlation across errors in the regressions. Note that the alternatives are not mutually exclusive in this case and the sum of the probabilities is greater than one. Table 4 shows the results. Farms with electricity are more likely to choose beef and dairy cattle and sheep. Large farms are more likely to choose any animal except for chickens. West African farmers are less likely to choose beef and dairy cattle but more likely to choose goats and sheep. These results are quite consistent with the results in Table 2 and Table 3, which use the primary animal and portfolio approaches.

The climate coefficients are significant and similar to the results in Table 2 and Table 3 . For example, with beef cattle the linear term is positive and the quadratic term is negative with respect to summer temperature. The linear term is negative and the quadratic term is positive with respect to summer temperature in the case of dairy cattle and sheep.

Figures $4 \mathrm{a}$ and $4 \mathrm{~b}$ plot the estimated probability response function with respect to temperature and precipitation respectively from the multivariate probit model. These plots suggest little difference from the primary animal approach except that the sum of the probabilities is greater than one. The probability of choosing beef cattle and dairy cattle decreases, the probability of choosing goats and sheep increases, and the probability of choosing chickens is hill-shaped with respect to annual mean temperature. Note that the mean temperature in the sample for beef cattle and dairy cattle is $19^{\circ} \mathrm{C}$, for goats and sheep $24^{\circ} \mathrm{C}$, and for chickens $21^{\circ} \mathrm{C}$. Precipitation 
responses for beef cattle, dairy cattle and sheep are similar to those of the primary animal approach. However, the goat and chicken probabilities start to decrease at a significantly large amount of rainfall.

\section{Climate change simulations}

\section{A. Uniform climate change scenarios}

We begin this analysis by examining some uniform climate change scenarios. In the warming scenarios, we increase existing temperatures by a constant amount across Africa. In the precipitation scenarios, we change rainfall proportionally by the same amount across Africa. Although these climate scenarios are not realistic, they provide a simple set of climate changes that allow one to see how the model behaves and to test whether the results are well-behaved. The scenarios explore changes of $+2.5^{\circ} \mathrm{C},+5.0^{\circ} \mathrm{C},+15 \%$ precipitation and $-15 \%$ precipitation across all of Africa.

Table 5 shows how climate change affects the decision of whether or not to engage in livestock management. A warming of $2.5^{\circ} \mathrm{C}$ increases the probability of engaging in livestock management by $5 \%$ and a further warming of $5^{\circ} \mathrm{C}$ raises the increased probability to $9 \%$. More rainfall reduces the probability and less rainfall increases the probability, but the effects are substantially smaller than the temperature change effects.

Table 6 shows how the probability of choosing a particular animal is predicted to change for each uniform scenario. For both the primary animal approach and the demand system, warming causes the probability of choosing beef cattle and chicken to decrease significantly and the probability of choosing goats and sheep to increase. The change for dairy cattle is positive but insignificant. As warming proceeds, these effects continue to increase. The portfolio approach predicts the same changes from warming except that dairy cattle decrease significantly. The rainfall effects are much smaller than the warming effects. All three choice models predict increases/decreases in rainfall will decrease/increase dairy cattle and sheep. This result is probably due to the effects precipitation has on the landscape between savanna and forest. The primary animal model predicts that increases/decreases in rainfall will increase/decrease goats and chickens. The demand system and portfolio models predict that more/less rainfall slightly increases/decreases the probability of beef cattle.

\section{B. AOGCM scenarios}

We also examine a set of climate change scenarios predicted by AOGCMs. These climate scenarios reflect the A1 scenarios in the IPCC's Special Report on Emissions Scenarios (SRES) (IPCC 2001) from the following models: Canadian Climate Center (CCC) (Boer et al. 2000), Center for Climate System Research (CCSR) (Emori et al. 1999), and Parallel Climate Model (PCM) (Washington et al. 2000). We examine country level climate change scenarios for 2000, 2020, 2060, and 2100. For each climate scenario, we add the climate model's predicted change 
in temperature to the baseline temperature in each district. We also multiply the climate models predicted percentage change in precipitation by the baseline precipitation in each district or province. This gives us a new climate for every district in Africa.

Table 7 summarizes the climate scenarios of the three models for the years 2020, 2060, and 2100. The models predict a broad set of scenarios consistent with the range of outcomes in the most recent IPCC report (Houghton et al. 2001). In 2100, PCM predicts a $2^{\circ} \mathrm{C}$ increase, CCSR a $4^{\circ} \mathrm{C}$ increase and CCC a $6^{\circ} \mathrm{C}$ increase in temperature in Africa. Rainfall predictions are noisier: PCM predicts an average $10 \%$ increase, CCC a $10 \%$ decrease and CCSR a $30 \%$ average decrease in rainfall in Africa. In addition to the mean rainfall in Africa varying substantially across the scenarios, there is also substantial variation in rainfall across countries within each scenario.

Examining the path of climate change over time reveals that temperatures are predicted to increase steadily until 2100 for all three models. Precipitation predictions, however, vary across time. CCC predicts a declining trend, CCSR an initial decrease, and then increase, and decrease again, and PCM an initial increase, and then decrease, and increase again.

We then use the parameters from our discrete continuous choice model in Table 1 to simulate the impacts of climate change on the livestock management under each AOGCM scenario. Table 8 describes how the probability of owning livestock changes with each climate scenario. The scenarios of all three climate models predict a 2-3\% increase in the probability of owning livestock by 2020 , and a $4-7 \%$ increase by 2060 . In 2100 , the impacts of the three climate scenarios diverge: CCC predicts a sharp increase in livestock ownership, PCM a moderate reduction from 2060 and CCSR a return to current conditions in 2100.

Table 9 shows how the probability of choosing each animal changes for each climate scenario, using the primary animal estimates (Table 2). All these climate scenarios predict that farmers will choose fewer beef cattle and chickens, but more goats and sheep. For the primary animal approach, the CCC and CCSR climate scenarios predict a gradually increasing loss of beef cattle over the next century, while the PCM scenario predicts an initial loss by 2020 and no change afterwards.

Table 10 shows how the probabilities of choosing each animal change according to the portfolio model estimates. (Table 3). Under all the climate scenarios, the probability of choosing beef cattle and chickens decreases and the probability of choosing sheep increases gradually over time, which is in accordance with the other approaches. The results from the portfolio approach, unlike the other approaches, however, predict that dairy cattle and goats will decrease as well.

Table 11 shows the results for the demand system approach (Table 4). The results are quite similar to the primary animal analysis, with decreasing beef cattle and chickens and increasing goats and sheep across all scenarios. Dairy cattle increase and decrease depending on the scenario. 


\section{Conclusion}

This paper quantifies the way African farmers have adapted livestock management to the varied climates found across the African continent. We examine whether farmers choose to adopt livestock and which species to manage. Using data from over 9000 farmers, a logit analysis of livestock ownership reveals that farmers are more likely to choose to manage livestock in warmer and drier locations. This result confirms observations that livestock tend to be located in hotter and drier locations around the world.

We examine species selections using three different approaches: primary animal approach, multivariate probit approach, and portfolio approach. All three approaches reveal that the probability of choosing beef cattle and dairy cattle decreases as temperature increases, but the probability of owning goats and sheep increases. The probability of choosing chickens has a hillshaped response to temperature. According to the primary animal and demand system approaches, more rainfall reduces the probability of choosing beef cattle, dairy cattle and sheep, but increases the probability of choosing goats and chickens. In contrast, the portfolio approach predicts precipitation has little effect on beef cattle and dairy cattle and causes the probability of choosing goats to decrease.

We simulate the magnitude of these effects across several uniform scenarios. Warming by $2.5^{\circ} \mathrm{C}$ increases the probability of managing livestock by $5 \%$ and a $5^{\circ} \mathrm{C}$ warming increases the probability by $9 \%$. Higher temperatures will move African farmers into livestock management. More precipitation, in contrast, reduces the probability that a farmer will choose livestock management. Warming moves farmers away from choosing cattle and chicken and towards choosing goats and sheep. The primary animal approach predicts a $2.5^{\circ} \mathrm{C}$ warming will decrease the probability of selecting beef cattle by $2 \%$ and chickens by $3 \%$, and that a $5^{\circ} \mathrm{C}$ warming will reduce beef by $4 \%$ and chickens by $7 \%$. Sheep replace these animals. Relative to the effects of warming, precipitation has very small effects on species choice.

We also simulate the livestock effects across three AOGCM climate scenarios. The AOGCM scenarios predict a 2-3\% increase in the probability of owning livestock by 2020, a 4-7\% increase by 2060 , and a $0-13 \%$ increase by 2100 . The wide range in outcomes reflects both temperature and precipitation differences across the climate scenarios. For both the primary animal and demand system analysis, all the climate warming scenarios predict that farmers will choose beef cattle and chicken less often, but goats and sheep more often. For example, the probability of choosing beef cattle decreases on average by $1 \%$ in $2020,2 \%$ in 2060, and $3 \%$ in 2100 for the primary animal analysis, and by $3 \%$ in $2020,4 \%$ in 2060 , and $5 \%$ in 2100 for the demand system analysis. In most scenarios, dairy cattle tend to decrease but there are exceptions. The portfolio approach predicts goats will decline due to rainfall effects.

In general, farmers will adapt to warming by slowly moving towards livestock management. Managing livestock in Africa is likely to be relatively more profitable than crops in future climate conditions. However, the species chosen will be slightly different than today, with less emphasis on cattle and chickens and more on goats and sheep. These changes may be especially hard on larger farms that currently specialize in cattle. Although this paper anticipates that there will be widespread adaptations, the changes envisioned are relatively minor. Farmers should have little difficulty making these transitions as climate change gradually unfolds. 
Of course, this study does not examine all conditions that may be relevant to the future. The paper does not consider technical change, although this is likely to be very important. It does not consider a shift in the GDP away from agriculture, although this would reduce the potential number of farmers at risk. It does not consider the effects of other climate-related factors such as changes in water flow, irrigation, and carbon dioxide fertilization. 


\section{REFERENCES}

Adams R et al., 1999. The economic effects of climate change on US agriculture. In Mendelsohn, R \& Neumann, J (eds), The Impact of Climate Change on the United States Economy. Cambridge, UK: Cambridge University Press.

Ausubel J, 1991. A second look at the impacts of climate change. American Scientist 79: 211221.

Barnett J, 2001. Adapting to climate change in Pacific Island countries: The problem of uncertainty. World Development 29: 977-993.

Boer G, Flato G \& Ramsden D, 2000. A transient climate change simulation with greenhouse gas and aerosol forcing: Projected climate for the 21 st century. Climate Dynamics 16: 427450.

Bryant CR et al., 2001. Adaptation in Canadian agriculture to climate variability and change. Climatic Change 45: 181-201.

Chib S \& Greenberg E, 1998. An analysis of multivariate probit models. Biometrika 85: 347361.

Chow G, 1983. Econometrics. New York: McGraw-Hill.

Dinar A, Hassan R, Kurukulasuriya P, Benhin J \& Mendelsohn R, 2006. The policy nexus between agriculture and climate change in Africa. A synthesis of the investigation under the GEF / WB Project, Regional Climate, Water and Agriculture: Impacts on and Adaptation of Agro-ecological Systems in Africa. CEEPA Discussion Paper No. 39, Centre for Environmental Economics and Policy in Africa, University of Pretoria.

Emori, S, Nozawa T, Abe-Ouchi A, Namaguti A \& Kimoto M, 1999. Coupled ocean-atmospheric model experiments of future climate change with an explicit representation of sulfate aerosol scattering. Journal of the Meteorological Society of Japan 77: 1299-1307.

Evenson RE, 2005. Agricultural technology and climate change impacts. Working Paper, Yale University.

Fafchamps M, Udry C \& Czukas K, 1998. Drought and saving in West Africa: Are livestock a buffer stock? Journal of Development Economics 55: 273-305.

Ford J \& Katondo K, 1977. The Distribution of Tsetse flies in Africa. Organization of African Unity, Nairobi, Kenya.

Houghton JT et al. (eds), 2001. Climate Change 2001: The Scientific Basis. Contribution of Working Group I to the third assessment report of the Intergovernmental Panel on Climate Change. Cambridge: Cambridge University Press. 
IPCC (Intergovernmental Panel on Climate Change), 2001, Climate Change 2001: The Scientific Basis. New York: Cambridge University Press.

Kelly DL, Kolstad CD \& Mitchell GT, 2005. Adjustment costs from environmental change. Journal of Environmental Economics and Management 50: 468-495.

Klein RJT, Nicholls RJ \& Mimura N, 1999. Coastal adaptation to climate change: Can the IPCC technical guidelines be applied? Mitigation and Adaptation Strategies for Global Change 4(3-4): 51-64.

Kurukulasuriya P \& Mendelsohn R, 2006. A Ricardian analysis of the impact of climate change on African cropland. CEEPA Discussion Paper No. 8, Centre for Environmental Economics and Policy in Africa, University of Pretoria.

Leary NA, 1999. A framework for benefit-cost analysis of adaptation to climate change and climate variability. Mitigation and Adaptation Strategies for Global Change 4(3-4): 307318.

McCarthy J, Canziani, OF, Leary, NA, Dokken DJ \& White C (eds), 2001. Climate Change 2001: Impacts, Adaptation, and Vulnerability. Contribution of Working Group II to the third assessment report of the Intergovernmental Panel on Climate Change. Cambridge: Cambridge University Press.

McFadden DL, 1973. Conditional logit analysis of qualitative choice behavior. In Zarembka P (ed.), Frontiers in Econometrics. New York: Academic Press.

McFadden DL, 1999. Chapter 1. Discrete Response Models. University of California at Berkeley, Lecture Notes.

Mendelsohn R, 2000. Efficient adaptation to climate change. Climatic Change 45: 583-600.

Mendelsohn R, Nordhaus W \& Shaw D, 1994. The impact of global warming on agriculture: A Ricardian analysis. American Economic Review 84: 753-771.

Mendelsohn RA, Basist A, Kogan F \& Kurukulasuriya P, 2006 (forthcoming). Measuring climate change impacts with satellite versus weather station data. Climatic Change.

Pittock B \& Jones RN, 2000. Adaptation to what and why? Environmental Monitoring and Assessment 61(1): 9-35.

Reilly J et al., 1996. Agriculture in a changing climate: Impacts and adaptations. In Watson R, Zinyowera M, Moss R \& Dokken D (eds), 1996. Climate Change 1995: Impacts, Adaptations, and Mitigation of Climate Change: Scientific-Technical Analyses, Cambridge: Cambridge University Press for the Intergovernmental Panel on Climate Change (IPCC).

Sankaran M et al., 2005. Determinants of woody cover in African savannas, Nature 438: 846849. 
Seo SN \& Mendelsohn R, 2006. Climate change impacts on animal husbandry in Africa: A Ricardian analysis. CEEPA Discussion Paper No. 9, Centre for Environmental Economics and Policy in Africa, University of Pretoria.

Smit B, McNabb D \& Smithers J, 1996. Agriculture adaptations to climate variation. Climatic Change 33: 7-29.

Smit B, Burton I, Klein RJT \& Wandel J, 2000. An anatomy of adaptation to climate change and variability. Climatic Change 45(1): 223-251.

Smit B \& Pilifosova O, 2001. Adaptation to climate change in the context of sustainable development and equity. In McCarthy JJ, Canziani OF, Leary NA, Dokken DJ \& White KS (eds), Climate Change 2001: Impacts, Adaptation, and vulnerability - Contribution of Working Group II to the Third Assessment Report of the Intergovernmental Panel on Climate Change. Cambridge, U.K.: Cambridge University Press.

Swinton S, 1988. Drought survival tactics of subsistence farmers in Niger. Human Ecology 16: $123-144$.

Train K, 2003. Discrete Choice Methods with Simulation, Cambridge, UK: Cambridge University Press.

Viglizzo EF, Roberto Z, Lertora F, Lopez G \& Bernardos J, 1997, Climate and land use change in field-crop ecosystems of Argentina Agriculture, Ecosystems and the Environment 66: 61-70.

Washington W et al., 2000. Parallel Climate Model (PCM): Control and transient scenarios. Climate Dynamics 16: 755-774.

Yohe G, Neumann J, Marshall P \& Ameden A, 1996. The economic costs of sea-level rise on developed property in the United States. Climate Change 32: 387-410. 
Table 1: Logit regression of whether or not to own livestock

\begin{tabular}{lccc}
\hline Variable & Estimate & Wald chi-sq & Odds ratio \\
\hline Intercept & -4.814 & 36.025 & \\
Temperature summer & 0.247 & 15.763 & 1.280 \\
Temperature summer & & & \\
sq & -0.005 & 15.343 & 0.995 \\
Precipitation summer & 0.010 & 30.788 & 1.010 \\
Precipitation summer & & & \\
sq & 0.000 & 37.903 & 1.000 \\
Temperature winter & -0.020 & 0.123 & 0.980 \\
Temperature winter sq & 0.004 & 4.625 & 1.004 \\
Precipitation winter & -0.018 & 40.700 & 0.982 \\
Precipitation winter sq & 0.000 & 36.037 & 1.000 \\
West Africa & -0.851 & 57.628 & 0.427 \\
\% pasture & 0.817 & 7.983 & 2.265 \\
\% Islam & 0.919 & 14.716 & 2.507 \\
Population density & 0.091 & 318.376 & 1.095 \\
Population density sq & -0.001 & 280.254 & 0.999 \\
\hline
\end{tabular}


Table 2: Multinomial logit 'primary animal' regressions of species choice

\begin{tabular}{|c|c|c|c|c|c|c|}
\hline Variable & Est. & $\begin{array}{l}\text { Beef cattle } \\
\text { Error! } \\
\text { Objects } \\
\text { cannot be } \\
\text { created } \\
\text { from } \\
\text { editing } \\
\text { field } \\
\text { codes. }\end{array}$ & OR & Est. & $\begin{array}{l}\text { Dairy cattle } \\
\text { Error! } \\
\text { Objects } \\
\text { cannot be } \\
\text { created from } \\
\text { editing field } \\
\text { codes. }\end{array}$ & OR \\
\hline Intercept & -2.916 & 1.450 & & 13.336 & 74.287 & \\
\hline Temperature summer & 0.496 & 6.711 & 1.642 & -1.145 & 100.922 & 0.318 \\
\hline $\begin{array}{l}\text { Temperature summer } \\
\text { sq }\end{array}$ & -0.014 & 11.261 & 0.986 & 0.019 & 58.532 & 1.019 \\
\hline Precipitation summer & 0.015 & 14.592 & 1.015 & -0.022 & 49.731 & 0.978 \\
\hline $\begin{array}{l}\text { Precipitation summer } \\
\text { sq }\end{array}$ & 0.000 & 28.270 & 1.000 & 0.000 & 15.070 & 1.000 \\
\hline Temperature winter & -0.556 & 19.712 & 0.573 & 0.175 & 2.290 & 1.192 \\
\hline $\begin{array}{l}\text { Temperature winter } \\
\text { sq }\end{array}$ & 0.018 & 23.700 & 1.018 & 0.004 & 1.571 & 1.004 \\
\hline Precipitation winter & -0.004 & 0.501 & 0.996 & -0.032 & 43.425 & 0.969 \\
\hline $\begin{array}{l}\text { Precipitation winter } \\
\text { sq }\end{array}$ & 0.000 & 0.439 & 1.000 & 0.000 & 9.098 & 1.000 \\
\hline West Africa & -1.088 & 22.092 & 0.337 & -3.092 & 226.729 & 0.045 \\
\hline Large farms & 4.097 & 540.972 & 60.178 & 2.654 & 416.886 & 14.209 \\
\hline Electricity & 0.785 & 17.854 & 2.192 & 0.599 & 13.550 & 1.821 \\
\hline Variable & Est. & $\begin{array}{l}\text { Goats } \\
\text { Error! } \\
\text { Objects } \\
\text { cannot be } \\
\text { created } \\
\text { from } \\
\text { editing } \\
\text { field } \\
\end{array}$ & OR & Est. & $\begin{array}{c}\text { Sheep } \\
\text { Error! } \\
\text { Objects } \\
\text { cannot be } \\
\text { created from } \\
\text { editing field } \\
\text { codes. }\end{array}$ & $\mathbf{O R}$ \\
\hline
\end{tabular}


codes.

\begin{tabular}{lcccccc}
\hline Intercept & 6.564 & 14.871 & & 12.307 & 51.906 & \\
Temperature summer & -0.804 & 50.026 & 0.448 & -0.803 & 43.024 & 0.448 \\
Temperature summer & & & & & & \\
sq & 0.016 & 48.575 & 1.016 & 0.014 & 33.097 & 1.014 \\
Precipitation summer & -0.007 & 6.668 & 0.993 & -0.007 & 4.020 & 0.993 \\
Precipitation summer & & & & & & \\
sq & 0.000 & 9.204 & 1.000 & 0.000 & 0.185 & 1.000 \\
Temperature winter & 0.174 & 1.511 & 1.191 & -0.404 & 12.038 & 0.668 \\
Temperature winter & & & & & & \\
sq & -0.001 & 0.019 & 0.999 & 0.015 & 22.158 & 1.015 \\
Precipitation winter & -0.024 & 24.591 & 0.977 & -0.027 & 23.462 & 0.974 \\
Precipitation winter & & & & & & \\
sq & 0.000 & 16.397 & 1.000 & 0.000 & 6.173 & 1.000 \\
West Africa & 0.446 & 6.735 & 1.562 & 0.935 & 20.778 & 2.547 \\
Large farms & 0.888 & 51.060 & 2.429 & 1.694 & 182.293 & 5.440 \\
Electricity & -0.048 & 0.112 & 0.953 & 0.320 & 4.606 & 1.378 \\
\hline
\end{tabular}

Likelihood ratio test: $\mathrm{P}<0.0001$, Lagrange multiplier test: $\mathrm{P}<0.0001$, Wald test: $\mathrm{P}<0.0001$ 
Table 3: Multinomial logit 'optimal portfolio' regression

\begin{tabular}{lcccccccc}
\hline & \multicolumn{2}{c}{ Beef cattle } & \multicolumn{2}{c}{ Goats } & \multicolumn{2}{c}{ Dairy cattle } & \multicolumn{2}{c}{ Sheep } \\
& Estimate & chi-sq & Estimate & chi-sq & Estimate & chi-sq & Estimate & chi-sq \\
\hline $\begin{array}{l}\text { Intercept } \\
\begin{array}{l}\text { Temperature } \\
\text { summer }\end{array}\end{array}$ & -15.382 & 13.310 & -6.828 & 6.010 & 8.947 & 12.000 & 1.964 & 0.530 \\
$\begin{array}{l}\text { Temperature } \\
\text { summer sq }\end{array}$ & -0.029 & 16.550 & -0.011 & 7.870 & 0.008 & 3.450 & -0.004 & 0.890 \\
$\begin{array}{l}\text { Precipitation } \\
\text { summer }\end{array}$ & 0.061 & 36.710 & -0.022 & 11.440 & -0.038 & 30.550 & -0.029 & 19.850 \\
$\begin{array}{l}\text { Precipitation } \\
\text { summer sq }\end{array}$ & 0.000 & 15.700 & 0.000 & 27.690 & 0.000 & 28.890 & 0.000 & 23.910 \\
$\begin{array}{l}\text { Temperature } \\
\text { winter }\end{array}$ & -0.934 & 15.260 & -0.218 & 0.870 & 0.014 & 0.000 & -0.278 & 1.660 \\
$\begin{array}{l}\text { Temperature } \\
\text { winter sq }\end{array}$ & 0.019 & 7.610 & 0.011 & 2.930 & 0.000 & 0.010 & 0.015 & 6.780 \\
$\begin{array}{l}\text { Precipitation } \\
\text { winter }\end{array}$ & 0.035 & 4.990 & 0.028 & 5.210 & 0.018 & 1.990 & 0.004 & 0.090 \\
$\begin{array}{l}\text { Precipitation } \\
\text { winter sq }\end{array}$ & 0.000 & 0.000 & 0.000 & 2.110 & 0.000 & 4.290 & 0.000 & 0.230 \\
$\begin{array}{l}\text { Big farm } \\
\begin{array}{l}\text { Electricity } \\
\hline\end{array}\end{array}$ & -0.147 & 0.600 & 1.928 & 212.510 & 1.256 & 93.180 & 1.685 & 171.960 \\
\hline & 7.740 & -0.472 & 10.360 & -0.046 & 0.080 & -0.716 & 24.500 \\
\hline
\end{tabular}




\begin{tabular}{|c|c|c|c|c|c|c|c|c|}
\hline & \multicolumn{2}{|c|}{ Chickens } & \multicolumn{2}{|c|}{$\begin{array}{l}\text { Goats } \\
+ \text { sheep }\end{array}$} & \multicolumn{2}{|c|}{$\begin{array}{c}\text { Goats } \\
+ \text { chickens }\end{array}$} & \multicolumn{2}{|c|}{$\begin{array}{c}\text { Goats + chickens } \\
\text { + sheep }\end{array}$} \\
\hline & Estimate & chi-sq & Estimate & chi-sq & Estimate & chi-sq & Estimate & chi-sq \\
\hline Intercept & -14.256 & 38.800 & -8.524 & 7.500 & -16.993 & 44.530 & -20.876 & 56.330 \\
\hline $\begin{array}{l}\text { Temperature } \\
\text { summer }\end{array}$ & 1.252 & 54.080 & 0.186 & 0.790 & 0.984 & 29.030 & 1.080 & 30.290 \\
\hline $\begin{array}{l}\text { Temperature } \\
\text { summer sq }\end{array}$ & -0.024 & 51.260 & -0.007 & 3.070 & -0.020 & 30.710 & -0.021 & 30.760 \\
\hline $\begin{array}{l}\text { Precipitation } \\
\text { summer }\end{array}$ & -0.011 & 3.830 & -0.036 & 29.720 & -0.010 & 2.450 & -0.008 & 1.600 \\
\hline $\begin{array}{l}\text { Precipitation } \\
\text { summer sq }\end{array}$ & 0.000 & 13.190 & 0.000 & 18.150 & 0.000 & 10.910 & 0.000 & 2.150 \\
\hline $\begin{array}{l}\text { Temperature } \\
\text { winter }\end{array}$ & -0.005 & 0.000 & 0.521 & 3.290 & 0.492 & 4.850 & 0.633 & 7.200 \\
\hline $\begin{array}{l}\text { Temperature } \\
\text { winter sq }\end{array}$ & -0.002 & 0.100 & 0.000 & 0.000 & -0.009 & 2.300 & -0.010 & 2.870 \\
\hline $\begin{array}{l}\text { Precipitation } \\
\text { winter }\end{array}$ & 0.036 & 11.810 & 0.013 & 0.980 & -0.006 & 0.300 & -0.006 & 0.280 \\
\hline $\begin{array}{l}\text { Precipitation } \\
\text { winter sq }\end{array}$ & 0.000 & 5.860 & 0.000 & 4.120 & 0.000 & 0.660 & 0.000 & 0.120 \\
\hline Large farm & 2.283 & 356.570 & 1.359 & 128.500 & 1.942 & 266.280 & 1.199 & 115.620 \\
\hline Electricity & -0.059 & 0.190 & -0.584 & 17.070 & -0.099 & 0.490 & -0.103 & 0.520 \\
\hline
\end{tabular}


Table 3: (continued)

\begin{tabular}{|c|c|c|c|c|c|c|c|c|c|c|}
\hline & $\begin{array}{c}\text { Dair } \\
+ \\
+ \text { ch }\end{array}$ & $\begin{array}{l}\text { cattle } \\
\text { ats } \\
\text { kens }\end{array}$ & $\begin{array}{r}\text { St } \\
+\mathbf{c h}\end{array}$ & $\begin{array}{l}\text { eep } \\
\text { ickens }\end{array}$ & $\begin{array}{r}\text { Da } \\
\text { ca } \\
+\mathrm{g} \\
+\mathrm{s}\end{array}$ & $\begin{array}{l}\text { iry } \\
\text { tle } \\
\text { bats } \\
\text { eep }\end{array}$ & $\begin{array}{l}\text { Dair } \\
+ \text { ch }\end{array}$ & $\begin{array}{l}\text { cattle } \\
\text { ckens }\end{array}$ & $\begin{array}{c}\text { Dai } \\
+ \\
+\mathrm{cl}\end{array}$ & $\begin{array}{l}\text { cattle } \\
\text { heep } \\
\text { ckens }\end{array}$ \\
\hline & Est & $\begin{array}{c}\text { chi- } \\
\text { sq }\end{array}$ & Est & chi-sq & Est & $\begin{array}{l}\text { chi- } \\
\text { sq }\end{array}$ & Est & $\begin{array}{c}\text { chi- } \\
\text { sq }\end{array}$ & Est & chi-sq \\
\hline Intercept & 7.60 & 8.26 & -6.58 & 4.57 & 5.02 & 2.58 & 3.36 & 1.55 & 0.94 & 0.11 \\
\hline $\begin{array}{l}\text { Temperature } \\
\text { summer }\end{array}$ & -0.13 & 0.47 & 0.33 & 2.38 & 0.40 & 3.38 & $\begin{array}{c}- \\
0.08\end{array}$ & 0.16 & 0.16 & 0.65 \\
\hline $\begin{array}{l}\text { Temperature } \\
\text { summer sq }\end{array}$ & 0.00 & 0.79 & -0.01 & 4.40 & $\begin{array}{c}- \\
0.01\end{array}$ & 6.54 & 0.00 & 0.37 & 0.00 & 0.77 \\
\hline $\begin{array}{l}\text { Precipitation } \\
\text { summer }\end{array}$ & -0.03 & 15.16 & 0.00 & 0.42 & 0.01 & 1.03 & $\begin{array}{c}- \\
0.04\end{array}$ & 42.79 & 0.04 & 23.22 \\
\hline $\begin{array}{l}\text { Precipitation } \\
\text { summer sq }\end{array}$ & 0.00 & 13.12 & 0.00 & 2.11 & 0.00 & 5.69 & 0.00 & 32.78 & 0.00 & 13.56 \\
\hline $\begin{array}{l}\text { Temperature } \\
\text { winter }\end{array}$ & -0.42 & 3.71 & 0.12 & 0.18 & $\begin{array}{c}- \\
0.12\end{array}$ & 0.22 & 0.21 & 1.25 & 0.50 & 3.65 \\
\hline $\begin{array}{l}\text { Temperature } \\
\text { winter sq }\end{array}$ & 0.02 & 6.95 & 0.00 & 0.27 & 0.01 & 1.86 & $\overline{-}$ & 0.87 & $-\overline{0}$ & 1.05 \\
\hline $\begin{array}{l}\text { Precipitation } \\
\text { winter }\end{array}$ & 0.00 & 0.02 & 0.00 & 0.00 & 0.03 & 2.96 & 0.01 & 1.55 & 0.00 & 0.17 \\
\hline $\begin{array}{l}\text { Precipitation } \\
\text { winter sq }\end{array}$ & 0.00 & 0.00 & 0.00 & 0.00 & 0.00 & 3.78 & 0.00 & 3.31 & 0.00 & 0.77 \\
\hline Large farm & 0.61 & 20.53 & 1.73 & 162.71 & $\overline{0} \cdot \overline{11}$ & 0.33 & 1.19 & 88.83 & 0.48 & 13.05 \\
\hline Electricity & 0.42 & 5.12 & -0.46 & 9.05 & 0.09 & 0.23 & 0.01 & 0.00 & 0.32 & 3.30 \\
\hline
\end{tabular}


Table 4: Multivariate probit 'demand system' regressions

\begin{tabular}{|c|c|c|c|c|c|c|}
\hline \multirow[b]{2}{*}{ Variable } & \multicolumn{2}{|c|}{ Beef cattle } & \multicolumn{2}{|c|}{ Dairy cattle } & \multicolumn{2}{|c|}{ Chickens } \\
\hline & Est & $\mathbf{T}$ & Est & $\mathbf{T}$ & Est & $\mathbf{T}$ \\
\hline Intercept & 0.692 & 5.850 & 1.888 & 12.470 & -1.210 & -7.310 \\
\hline $\begin{array}{l}\text { Temperature } \\
\text { summer }\end{array}$ & 0.072 & 8.420 & -0.107 & -9.840 & 0.091 & 7.630 \\
\hline $\begin{array}{l}\text { Temperature } \\
\text { summer sq }\end{array}$ & -0.001 & -8.450 & 0.002 & 7.400 & -0.002 & -6.580 \\
\hline $\begin{array}{l}\text { Precipitation } \\
\text { summer }\end{array}$ & 0.003 & 11.710 & -0.002 & -6.920 & 0.001 & 2.900 \\
\hline $\begin{array}{l}\text { Precipitation } \\
\text { summer sq }\end{array}$ & 0.000 & 0.000 & 0.000 & 0.000 & 0.000 & 0.000 \\
\hline Temperature winter & -0.167 & -18.910 & 0.021 & 1.850 & 0.105 & 8.500 \\
\hline $\begin{array}{l}\text { Temperature winter } \\
\text { sq }\end{array}$ & 0.004 & 16.780 & 0.000 & 1.030 & -0.004 & -9.980 \\
\hline Precipitation winter & 0.002 & 3.620 & -0.005 & -7.760 & 0.000 & -0.550 \\
\hline $\begin{array}{l}\text { Precipitation winter } \\
\text { sq }\end{array}$ & 0.000 & 0.000 & 0.000 & 0.000 & 0.000 & 0.000 \\
\hline West Africa & -0.066 & -4.190 & -0.520 & -25.580 & 0.082 & 3.730 \\
\hline Large farms & 0.211 & 20.420 & 0.295 & 23.580 & -0.054 & -3.670 \\
\hline Electricity & 0.090 & 6.850 & 0.067 & 3.960 & -0.185 & -10.150 \\
\hline
\end{tabular}

Goats

Sheep

\begin{tabular}{lcccc} 
Variable & Est & T & Est & T \\
\hline $\begin{array}{l}\text { Intercept } \\
\begin{array}{l}\text { Temperature } \\
\text { summer }\end{array}\end{array}$ & 0.111 & 0.650 & 1.270 & 7.540 \\
$\begin{array}{l}\text { Temperature } \\
\text { summer sq }\end{array}$ & 0.031 & 2.530 & -0.054 & -4.420 \\
$\begin{array}{l}\text { Precipitation } \\
\text { summer }\end{array}$ & -0.001 & -2.850 & 0.001 & 2.980 \\
Precipitation & 0.000 & -1.140 & 0.000 & -1.050 \\
\hline
\end{tabular}




\begin{tabular}{lcccc}
\hline summer sq & & & & \\
Temperature winter & -0.015 & -1.180 & -0.025 & -1.950 \\
$\begin{array}{l}\text { Temperature winter } \\
\text { sq }\end{array}$ & 0.001 & 2.460 & 0.002 & 4.140 \\
Precipitation winter & -0.003 & -4.720 & -0.003 & -4.510 \\
Precipitation winter & & & & \\
sq & 0.000 & 0.000 & 0.000 & 0.000 \\
West Africa & 0.204 & 8.900 & 0.123 & 5.440 \\
Large farms & 0.155 & 10.630 & 0.248 & 17.180 \\
Electricity & -0.061 & -3.210 & 0.037 & 2.000 \\
\hline
\end{tabular}


Table 5: Change in probabilities of choosing livestock from uniform climate change scenarios

\begin{tabular}{lccc}
\hline Scenarios & $\begin{array}{c}\text { Change in } \\
\text { probability }\end{array}$ & Scenarios & $\begin{array}{c}\text { Change in } \\
\text { probability }\end{array}$ \\
\hline Baseline probability & $72.7 \%$ & & \\
Increase temperature & $+4.8 \%$ & $\begin{array}{c}\text { Increase rain } \\
15 \%\end{array}$ & $-0.6 \%$ \\
2.5 C & & Decrease rain & \\
Increase temperature 5 & $+8.8 \%$ & $15 \%$ & $+0.4 \%$ \\
$\mathrm{C}$ & & & \\
\hline
\end{tabular}

Table 6: Change in the probabilities of selecting species in each uniform climate change scenario

Scenarios cattle Dairy cattle Goats Sheep Chickens

\begin{tabular}{lccccc}
\hline \multicolumn{7}{c}{ Primary animal analysis } \\
Baseline probability & $11.8 \%$ & $23.1 \%$ & $23.4 \%$ & $19.4 \%$ & $22.3 \%$ \\
Increase temp 2.5 ${ }^{\circ} \mathrm{C}$ & $-1.7 \%$ & $0.4 \%$ & $0.8 \%$ & $3.3 \%$ & $-2.8 \%$ \\
Increase temp 5 ${ }^{\circ} \mathrm{C}$ & $-3.8 \%$ & $2.1 \%$ & $0.0 \%$ & $8.7 \%$ & $-7.0 \%$ \\
Decrease rain 15\% & $-0.3 \%$ & $1.8 \%$ & $-1.2 \%$ & $1.1 \%$ & $-1.4 \%$ \\
Increase rain 15\% & $-0.1 \%$ & $-1.5 \%$ & $1.5 \%$ & $-1.1 \%$ & $1.0 \%$ \\
\hline \multicolumn{7}{c}{ Demand system analysis } \\
Baseline probability & $35.5 \%$ & $56.1 \%$ & $63.0 \%$ & $58.8 \%$ & $71.6 \%$ \\
Increase temp 2.5 $\mathrm{C}$ & $-3.7 \%$ & $0.1 \%$ & $5.1 \%$ & $5.6 \%$ & $-7.4 \%$ \\
Increase temp 5 ${ }^{\circ} \mathrm{C}$ & $-4.6 \%$ & $1.7 \%$ & $10.7 \%$ & $13.2 \%$ & $-20.6 \%$ \\
Decrease rain 15\% & $-1.0 \%$ & $2.7 \%$ & $0.3 \%$ & $2.3 \%$ & $-0.3 \%$ \\
Increase rain 15\% & $0.6 \%$ & $-2.4 \%$ & $-0.1 \%$ & $-2.5 \%$ & $0.1 \%$ \\
\hline \multicolumn{7}{c}{ Optimal portfolio analysis } \\
Baseline probability & $4.8 \%$ & $26.3 \%$ & $54.5 \%$ & $45.0 \%$ & $63.7 \%$ \\
Increase temp 2.5 ${ }^{\circ} \mathrm{C}$ & $-1.8 \%$ & $-7.2 \%$ & $4.4 \%$ & $7.1 \%$ & $-9.7 \%$ \\
\hline
\end{tabular}




\begin{tabular}{lccccc}
\hline Increase temp $5{ }^{\circ} \mathrm{C}$ & $-2.8 \%$ & $-11.5 \%$ & $5.3 \%$ & $14.2 \%$ & $-22.0 \%$ \\
Decrease rain $15 \%$ & $-1.5 \%$ & $2.1 \%$ & $0.1 \%$ & $2.7 \%$ & $-0.2 \%$ \\
Increase rain $15 \%$ & $2.2 \%$ & $-1.9 \%$ & $-0.2 \%$ & $-2.6 \%$ & $-0.4 \%$ \\
\hline
\end{tabular}


Table 7: AOGCM climate scenarios

\begin{tabular}{lcccc}
\hline & Current & 2020 & 2060 & 2100 \\
\hline Temperature $\left({ }^{\circ} \mathbf{C}\right)$ & & & & \\
CCC & 23.29 & 24.94 & 26.85 & 29.96 \\
CCSR & 23.29 & 25.27 & 26.17 & 27.39 \\
PCM & 23.29 & 23.95 & 24.94 & 25.79 \\
\hline Rainfall & & & & \\
$($ mm/month $)$ & 79.75 & 76.84 & 71.86 & 65.08 \\
CCC & 79.75 & 73.99 & 76.67 & 62.44 \\
CCSR & 79.75 & 89.58 & 80.72 & 83.18 \\
PCM & & & & \\
\hline
\end{tabular}

Table 8: Predicted change in the probability of choosing livestock from AOGCM scenarios

\begin{tabular}{lllll}
\hline Scenarios & Baseline & $\begin{array}{c}\text { Change in } \\
\mathbf{2 0 2 0}\end{array}$ & $\begin{array}{c}\text { Change in } \\
\mathbf{2 0 6 0}\end{array}$ & $\begin{array}{c}\text { Change in } \\
\mathbf{2 1 0 0}\end{array}$ \\
\hline CCC & $72.4 \%$ & $+3.1 \%$ & $+3.5 \%$ & $+12.2 \%$ \\
CCSR & $72.4 \%$ & $+3.1 \%$ & $+4.5 \%$ & $0.0 \%$ \\
PCM & $72.4 \%$ & $+2.1 \%$ & $+6.7 \%$ & $+5.1 \%$ \\
\hline
\end{tabular}


Table 9: 'Primary animal' analysis of the change in the probability of selecting species in each AOGCM climate scenario

\begin{tabular}{|c|c|c|c|c|c|}
\hline & Beef cattle & Dairy cattle & Goats & Sheep & Chickens \\
\hline \multicolumn{6}{|c|}{ Primary animal analysis } \\
\hline \multicolumn{6}{|l|}{2020} \\
\hline $\mathrm{CCC}$ & $-1.6 \%$ & $1.3 \%$ & $1.8 \%$ & $1.9 \%$ & $-3.4 \%$ \\
\hline CCSR & $-0.5 \%$ & $-0.1 \%$ & $1.6 \%$ & $1.9 \%$ & $-2.8 \%$ \\
\hline PCM & $-2.1 \%$ & $-1.4 \%$ & $5.5 \%$ & $1.2 \%$ & $-3.3 \%$ \\
\hline \multicolumn{6}{|l|}{2060} \\
\hline $\mathrm{CCC}$ & $-1.7 \%$ & $-1.5 \%$ & $4.7 \%$ & $2.9 \%$ & $-4.4 \%$ \\
\hline CCSR & $-1.2 \%$ & $4.4 \%$ & $-1.9 \%$ & $2.1 \%$ & $-3.4 \%$ \\
\hline PCM & $-2.1 \%$ & $4.0 \%$ & $-2.7 \%$ & $8.6 \%$ & $-7.9 \%$ \\
\hline \multicolumn{6}{|l|}{2100} \\
\hline $\mathrm{CCC}$ & $-3.9 \%$ & $6.8 \%$ & $-5.7 \%$ & $16.7 \%$ & $-13.8 \%$ \\
\hline CCSR & $-3.3 \%$ & $-0.1 \%$ & $4.6 \%$ & $1.9 \%$ & $-3.1 \%$ \\
\hline PCM & $-2.1 \%$ & $-0.9 \%$ & $4.3 \%$ & $4.0 \%$ & $-5.4 \%$ \\
\hline
\end{tabular}


Table 10: 'Optimal portfolio' analysis of the change in the probability of selecting species in each AOGCM climate scenario

Beef cattle Dairy cattle Goats Sheep Chickens

Optimal portfolio analysis

\begin{tabular}{rcccccc}
\hline 2020 & & & & & \\
& CCC & $-4.3 \%$ & $-9.5 \%$ & $-0.8 \%$ & $21.7 \%$ & $-28.8 \%$ \\
& CCSR & $-4.3 \%$ & $-10.1 \%$ & $-0.6 \%$ & $21.0 \%$ & $-28.4 \%$ \\
& PCM & $-3.4 \%$ & $-13.8 \%$ & $-4.6 \%$ & $14.9 \%$ & $-35.4 \%$ \\
\hline 2060 & & & & & \\
& CCC & $-3.6 \%$ & $-15.3 \%$ & $-5.8 \%$ & $16.8 \%$ & $-36.6 \%$ \\
& CCSR & $-3.9 \%$ & $-8.8 \%$ & $-1.3 \%$ & $21.4 \%$ & $-31.7 \%$ \\
& PCM & $-4.6 \%$ & $-12.8 \%$ & $-5.6 \%$ & $27.3 \%$ & $-35.2 \%$ \\
\hline \multirow{2}{*}{2100} & & & & & $-45.8 \%$ \\
& CCC & $-4.6 \%$ & $-17.7 \%$ & $-10.6 \%$ & $33.8 \%$ & $-36.2 \%$ \\
& CCSR & $-3.2 \%$ & $-15.9 \%$ & $-4.2 \%$ & $20.6 \%$ & $-39.7 \%$ \\
\hline
\end{tabular}


Table 11: 'Demand system' analysis of the change in the probability of selecting species in each AOGCM climate scenario

\begin{tabular}{|c|c|c|c|c|c|}
\hline & Beef cattle & Dairy cattle & Goats & Sheep & Chickens \\
\hline \multicolumn{6}{|c|}{ Demand system analysis } \\
\hline \multicolumn{6}{|l|}{2020} \\
\hline $\mathbf{C C C}$ & $-2.8 \%$ & $0.7 \%$ & $3.9 \%$ & $4.3 \%$ & $-5.9 \%$ \\
\hline CCSR & $-1.9 \%$ & $-2.4 \%$ & $3.9 \%$ & $3.9 \%$ & $-5.8 \%$ \\
\hline PCM & $-6.1 \%$ & $-8.1 \%$ & $5.4 \%$ & $-4.8 \%$ & $-6.4 \%$ \\
\hline \multicolumn{6}{|l|}{2060} \\
\hline $\mathrm{CCC}$ & $-5.1 \%$ & $-9.2 \%$ & $6.8 \%$ & $-1.7 \%$ & $-9.4 \%$ \\
\hline CCSR & $-3.2 \%$ & $4.1 \%$ & $4.7 \%$ & $4.3 \%$ & $-9.0 \%$ \\
\hline PCM & $-2.0 \%$ & $2.9 \%$ & $9.6 \%$ & $13.2 \%$ & $-18.9 \%$ \\
\hline \multicolumn{6}{|l|}{2100} \\
\hline $\mathrm{CCC}$ & $-0.3 \%$ & $7.1 \%$ & $17.1 \%$ & $23.2 \%$ & $-40.5 \%$ \\
\hline CCSR & $-8.1 \%$ & $-4.1 \%$ & $6.2 \%$ & $5.0 \%$ & $-12.3 \%$ \\
\hline PCM & $-5.2 \%$ & $-9.5 \%$ & $8.4 \%$ & $-0.6 \%$ & $-14.4 \%$ \\
\hline
\end{tabular}




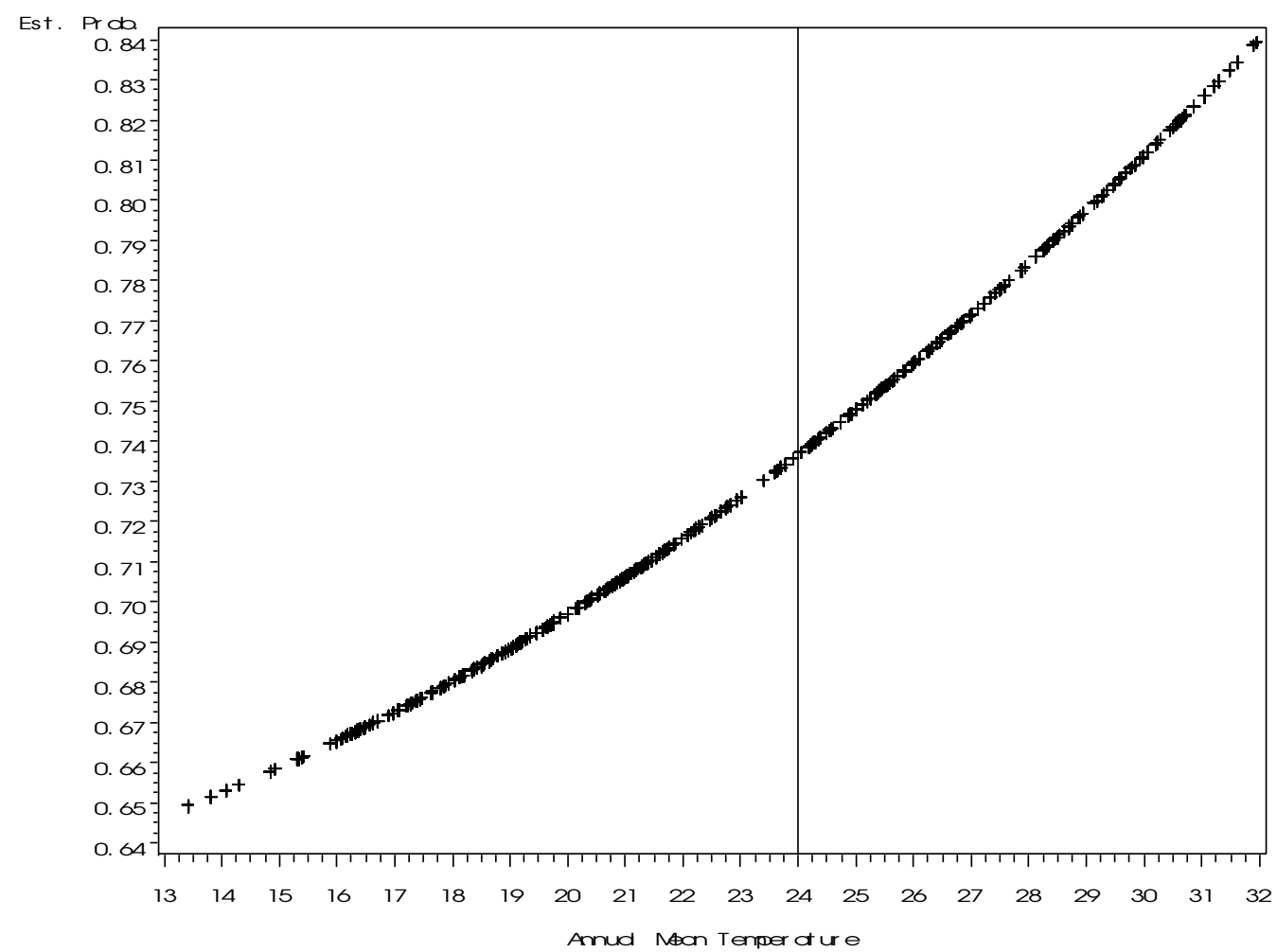

Figure 1a: The effect of annual temperature on the probability of owning livestock 


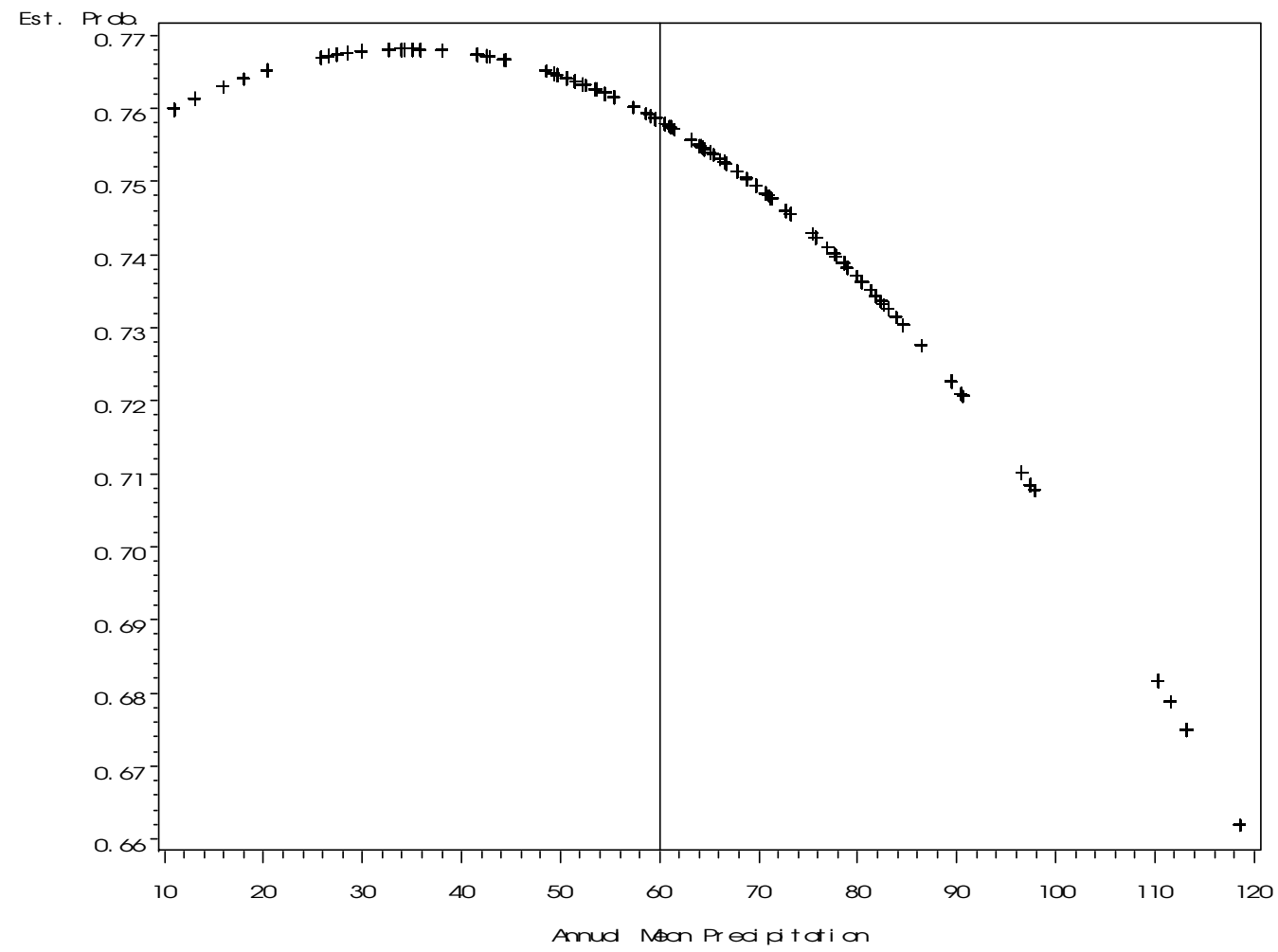

Figure 1b: The effect of annual precipitation on the probability of owning livestock 


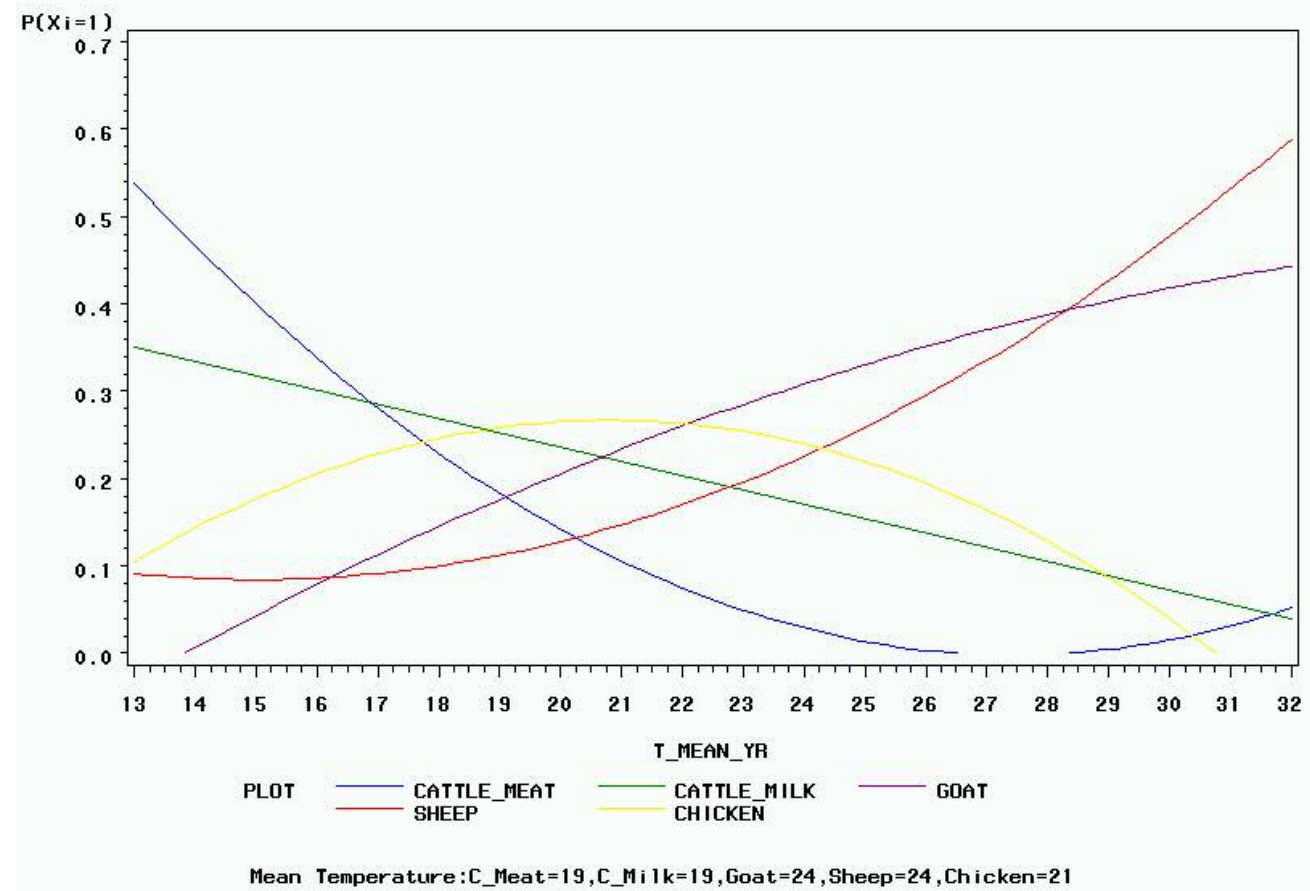

Figure 2a: The effect of annual temperature on the probability of species choice: Primary animal approach 


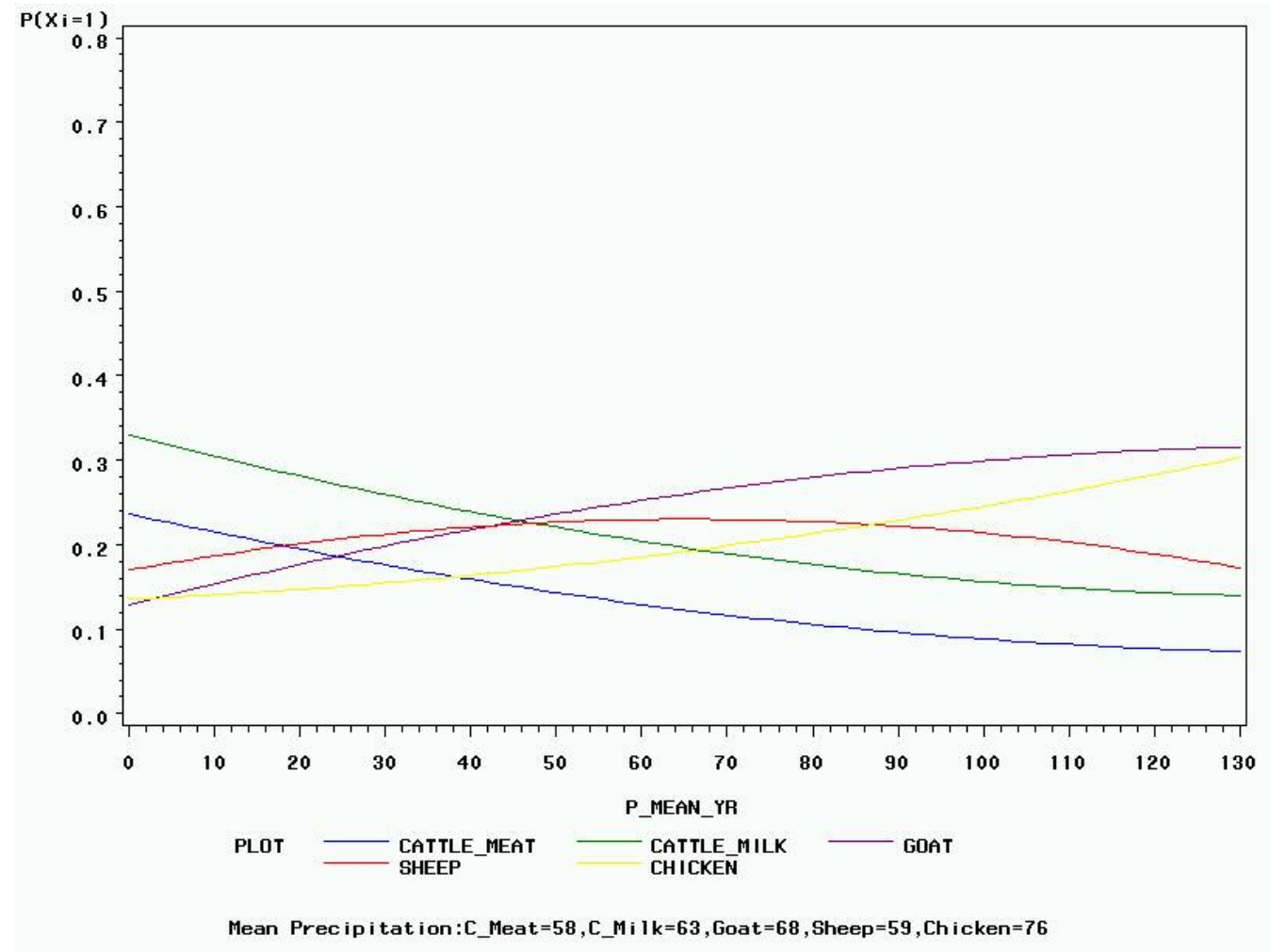

Figure 2b: The effect of annual precipitation on the probability of species choice: Primary animal approach 


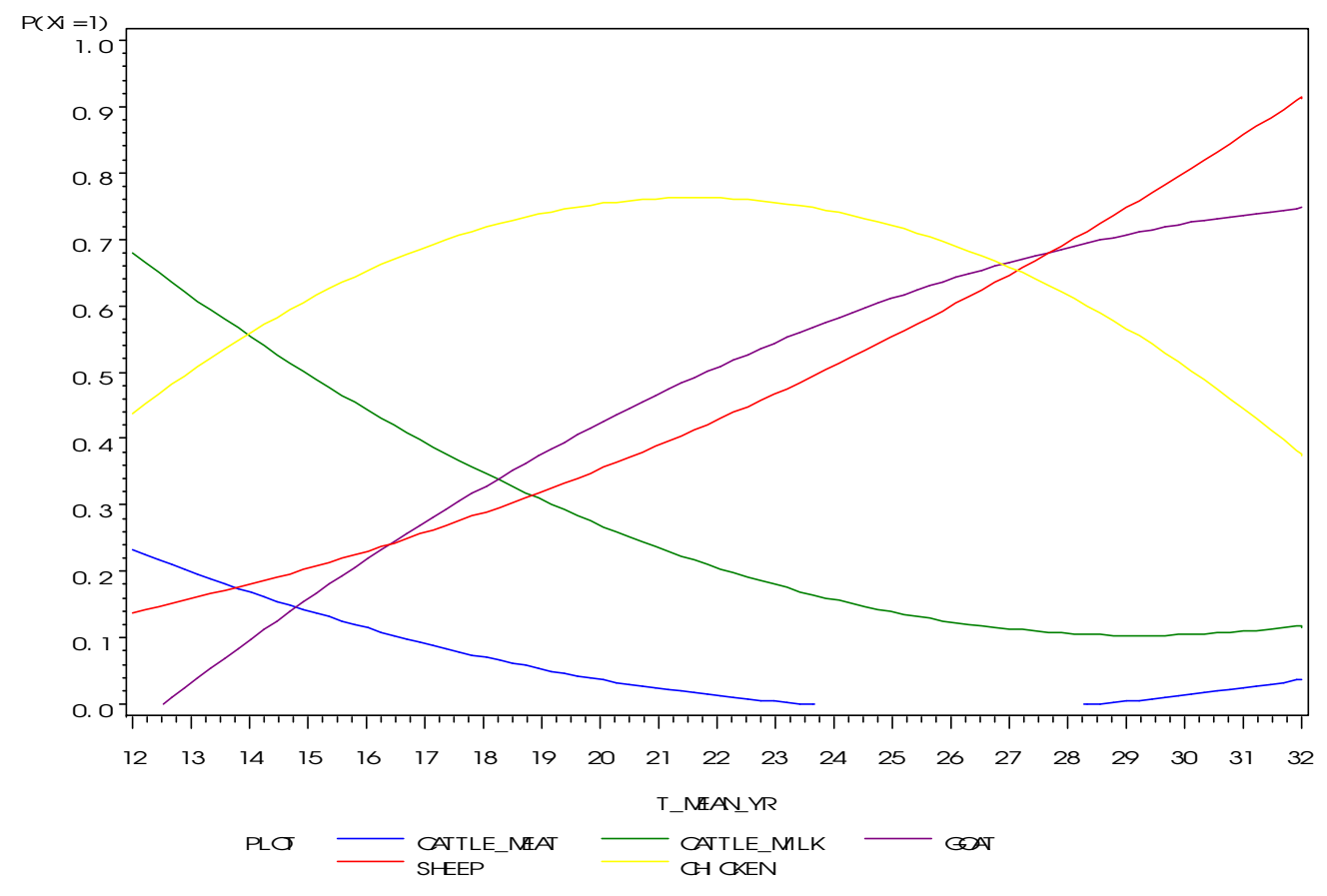

Figure 3a: The effect of annual temperature on the probability of species choice: Portfolio approach 


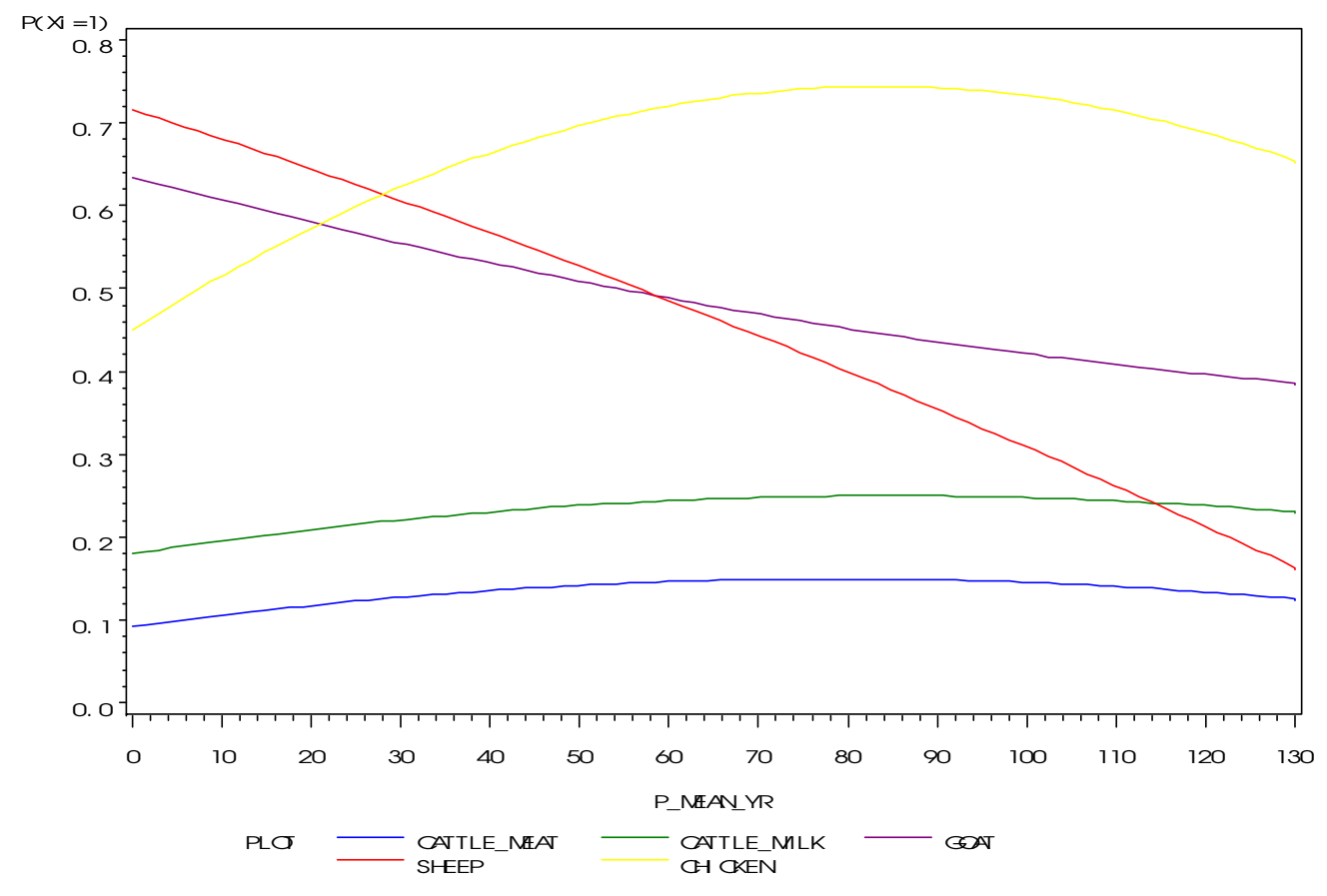

Figure 3b: The effect of annual precipitation on the probability of species choice: Portfolio approach 


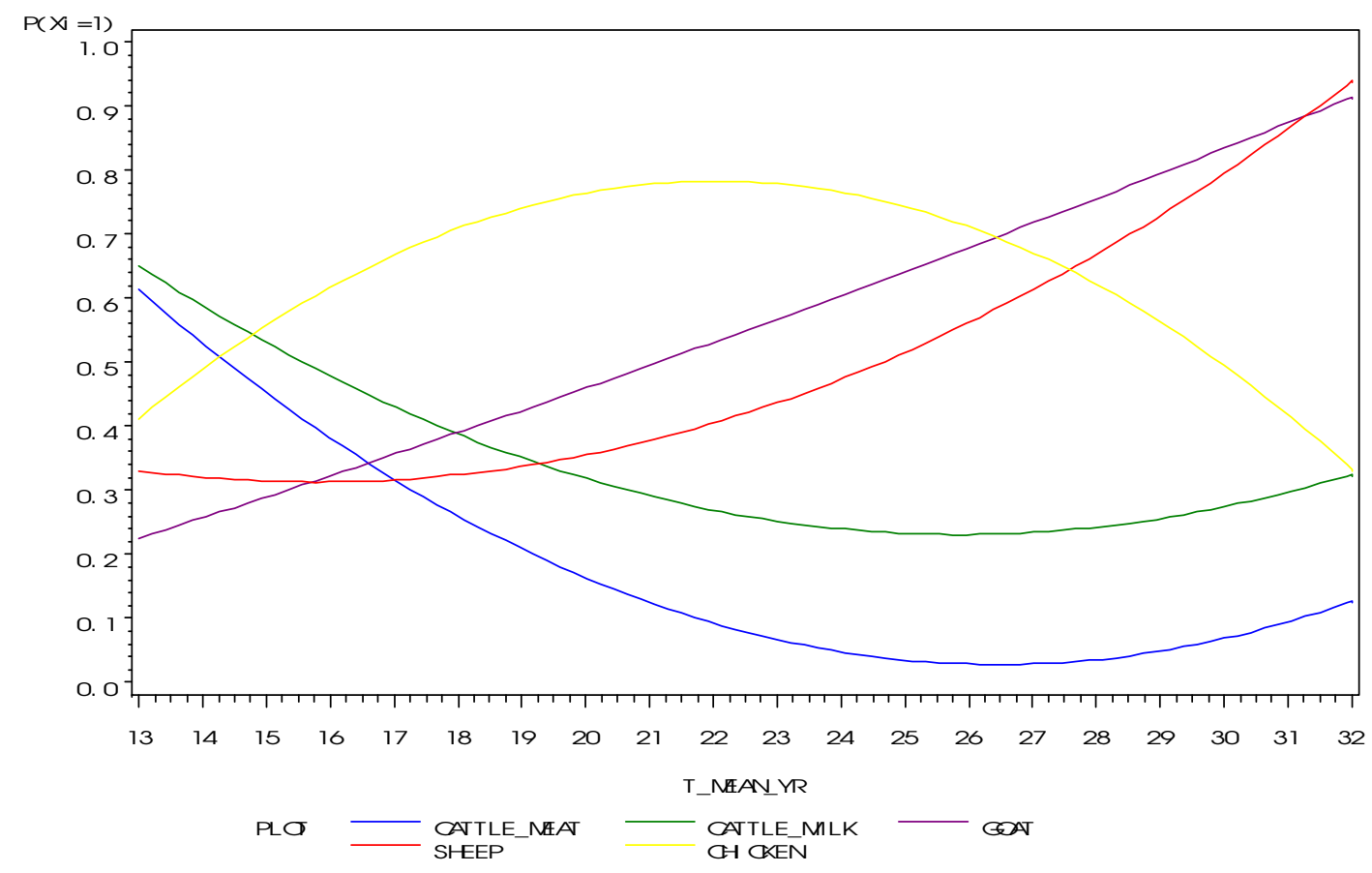

Figure 4a: The effect of annual temperature on the probability of species choice: Demand system approach 


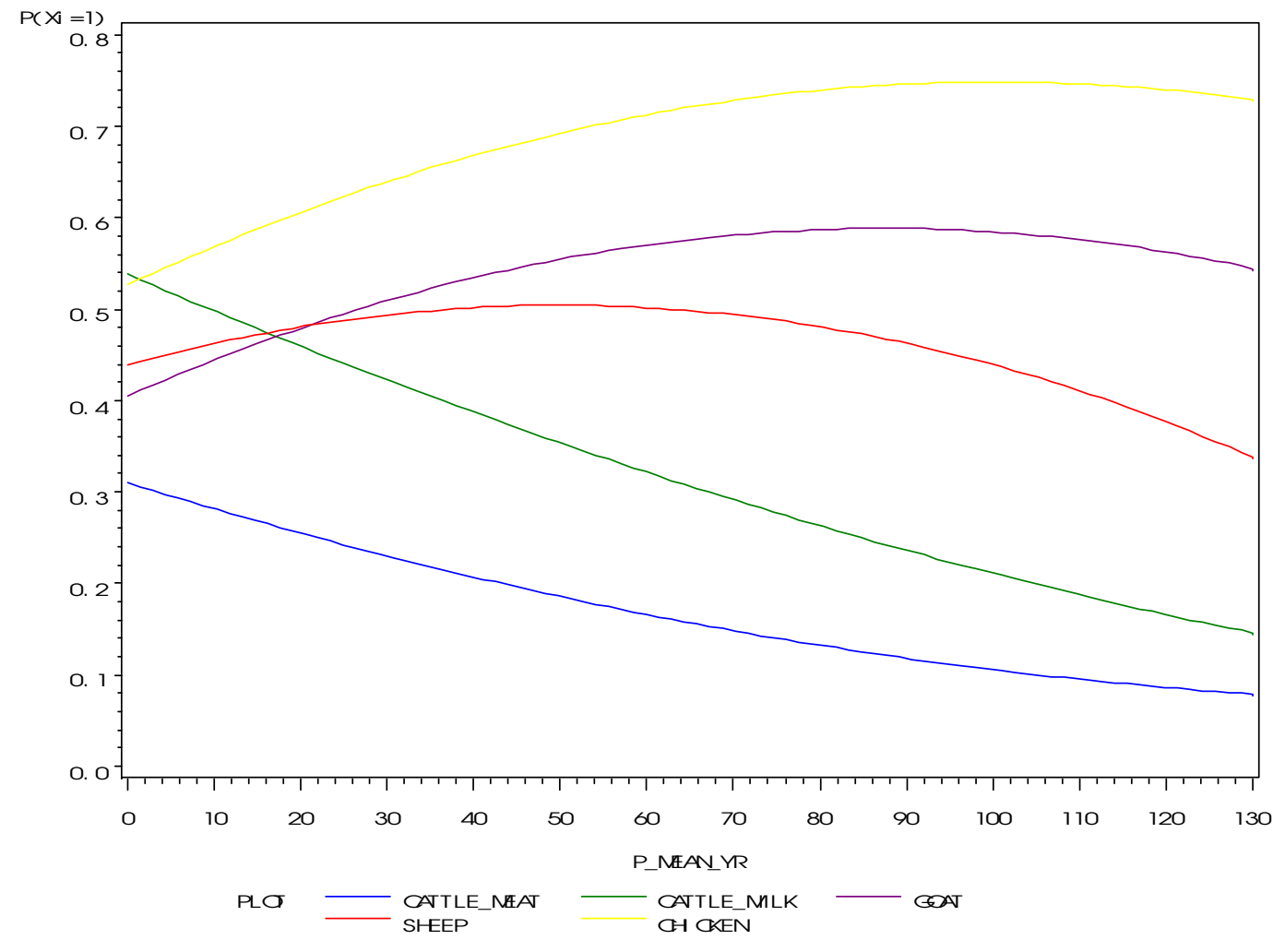

Figure 4b: The effect of annual precipitation on the probability of species choice: Demand system approach

wb1 12742

M:lidulidu1 \EANNETT\To be numbered\wps4277.doc

07/10/2007 10:51:00 AM 